\title{
Interest of Beta-2-Microglobilin Plasma Assay in Iterative Haemodialysis in the Nephrology and Haemodialysis Department of University Teaching Hospital of Point G, Bamako, Mali
}

\author{
Saharé Fongoro',2, Magara Samaké2,3, Seydou Sy1,2*, Hamadoun Yattara',2, Djénèba Diallo",2, \\ Jacques Coulibaly4, Moctar Coulibaly5, Aboubacar Sidiki Fofana1, Atabième Kodio', \\ Djénéba Maiga6, Aboudou M. Dolo', Moustapha Tangara1,2, Nouhoum Coulibaly1, \\ Brahima Dégoga1, Ibrahima Koné7
}

\author{
${ }^{1}$ Nephrology and Haemodialysis Department of the University Teaching Hospital of Point-G, Bamako, Mali \\ ${ }^{2}$ Faculty of Medicine of Bamako, Bamako, Mali \\ ${ }^{3}$ Nephrology Unit of the Fousseyni DAOU Hospital in Kayes, Kayes, Mali \\ ${ }^{4}$ Nephrology Unit of Ségou Hospital, Ségou, Mali \\ ${ }^{5}$ Nephrology Unit of the Mali GAVARDO Hospital of Sébénicoro, Bamako, Mali \\ ${ }^{6} \mathrm{Nephrology}$ Unit of Sikasso Hospital, Sikasso, Mali \\ ${ }^{7}$ Nephrology Unit of Somino DOLO Hospital in Mopti, Mopti, Mali \\ Email: *seydousy2002@yahoo.fr
}

How to cite this paper: Fongoro, S., Samaké, M., Sy, S., Yattara, H., Diallo, D., Coulibaly, J., Coulibaly, M., Fofana, A.S., Kodio, A., Maiga, D., Dolo, A.M., Tangara, M., Coulibaly, N., Dégoga, B. and Koné, I. (2020) Interest of Beta-2-Microglobilin Plasma Assay in Iterative Haemodialysis in the Nephrology and Haemodialysis Department of University Teaching Hospital of Point G, Bamako, Mali. Open Journal of Nephrology, 10, 282-289.

https://doi.org/10.4236/ojneph.2020.104028

Received: August 23, 2020

Accepted: October 24, 2020

Published: October 27, 2020

\begin{abstract}
Beta-2-microglobulin (B2M) is a low molecular weight polypeptide $(11,800$ $\mathrm{Da}$ ) that exists in a free form and a form bound to cell membranes (light chains of HLA class I molecules). Their dosage is used in the exploration and monitoring of renal function in haemodialysis patients, hence the interest of this study, the objective of which is to study the different players involved in the increase of beta-2-microglobulin. Materials and Methods: This was a prospective and descriptive study from January $1^{\text {st }}, 2017$ to August 31, 2017 (08 months). All patients with chronic hemodialysis for 3 years or more were included. We analyzed sociodemographic, clinical and paraclinical data. Results: We collected 50 patients. The mean age was $50 \pm 4.6$ years with extremes of 30 and 82 years. The female sex predominated (52\%). Chronic end-stage renal failure was hypertensive (86\%), diabetic (4\%). All patients benefited from intermittent hemodialysis for 8 hours per week using a low permeability membrane (cuprophane). The average duration of hemodialysis was $68 \pm 6.4$ months with extremes of 36 and 204 months. Twenty percent (20\%) and four percent (4\%) of chronic dialysis patients had joint pain and sensory deficit. Phalen's sign was positive in $2 \%$ ( 1 case), Tinel's sign in $2 \%$ ( 1
\end{abstract}


Copyright () 2020 by author(s) and Scientific Research Publishing Inc. This work is licensed under the Creative Commons Attribution International License (CC BY 4.0).

http://creativecommons.org/licenses/by/4.0/

Open Access case) and carpal tunnel syndrome in $2 \%$ ( 1 case). The mean serum beta-2-microglobulin level was $58.34 \mathrm{ng} / \mathrm{l}$ with extremes of 16.99 and 112.24 $\mathrm{ng} / \mathrm{l}$. There was a correlation between hypertensive nephropathies and beta-2-microglobulin levels above $50 \mathrm{ng} / \mathrm{l}(\mathrm{P}<0.001)$. The mortality rate was $6 \%$. Conclusion: Our study has objectified factors such as inadequate dialysis ( 8 hours/week), use of low permeability membrane in the increase of beta-2-microglobulin. The increase in serum beta-2-microglobulin levels in our patients is evidence of poor purification of medium molecules. Its reduction can be established by improving the quality of dialysis, in particular by using a high-permeability membrane.

\section{Keywords}

Chronic Hemodialysis, Beta-2-Microglobulin, Carpal Tunnel Syndrome

\section{Introduction}

Beta-2-microglobulin (B-2-M) was discovered in 1968 by Berggard et al. in the urine of patients with Wilson's disease or chronic cadmium intoxication [1]. It is a low molecular weight polypeptide that exists in free form and bound to cell membranes (light chain of class 1 histocompatibility molecules). In adults, serum B-2-M is stable with usual values between 1.1 and $2.4 \mathrm{ng} / \mathrm{l}$ [2]. This protein is filtered in the kidney by the glomeruli and reabsorbed through the proximal bypass tube. In case of renal failure, the serum level of beta-2-microglobulin increases. This elevation is the cause of several complications in chronic hemodialysis patients, including beta-2-microglobulin amyloidosis, which causes osteoarticular manifestations [3]. Per dialytic monitoring of beta-2-microglobulin is currently considered a quality criterion for extra-renal treatment [3], hence the interest of its dosage in chronic hemodialysis to establish its prevalence in our context.

\section{Materials and Methods}

This was a prospective and descriptive study and involved chronic hemodialysis patients who started dialysis 3 years or more ago. The study was conducted over an eight (8) month period from January $1^{\text {st }}, 2017$ to August 31, 2017. All chronic hemodialysis patients with 3 years or more of chronic hemodialysis were included. The questionnaire included sociodemographic data (age, gender, occupation, body mass index, dominant limb), clinical data (paresthesia, pain in the median nerve territory, presence of sensory deficit in the median nerve territory) and paraclinical data (blood count, serum calcium, phosphorus, parathormone, vitamin D3, CRP, B2-microglobulin which was quantitatively determined by immunological technique on a COBAE411 ROCH automaton and the laboratory standards for beta-2-microglobulin were 0.8 to $2.2 \mathrm{ng} / \mathrm{l}$ and inflammation was defined for CRP $>0.6 \mathrm{mg} / \mathrm{L}$. 
1) Operationaldefinitions:

Normal blood calcium in dialysis patients is $(2.1-2.6 \mathrm{mmol} / \mathrm{l})$.

Hypocalcemia $=$ calcemia $<2.1 \mathrm{mmol} / \mathrm{L}$.

Hypercalcemia $=$ calcemia $>2.6 \mathrm{mmol} / 1$.

Normal phosphorus is 0.81 to $1.45 \mathrm{mmol} / \mathrm{l}$.

Hypophosphatemia $=$ phosphatemia $<0.81 \mathrm{mmol} / \mathrm{L}$.

Hyperphosphatemia $=$ phosphatemia $>1.45 \mathrm{mmol} / 1$.

Secondary hyperparathyroidism is defined as parathyroid hormone levels greater than 9 times the upper limit of normal (>585 pg/ml).

Hypoparathyroidism: Intact PTH less than twice the upper limit of normal (130 pg/ml).

Native Vitamin D

- Normal: between 30 and $50 \mathrm{ng} / \mathrm{ml}$.

- Relative deficiency: between 10 and 29 pg/ml.

- Absolutedeficiency: $<10 \mathrm{ng} / \mathrm{ml}$.

Anemia was defined as hemoglobin $<13 \mathrm{~g} / \mathrm{dl}$ in males and $<12 \mathrm{~g} / \mathrm{dl}$ in females and the elderly.

Grade 0: $>11 \mathrm{~g} / \mathrm{dl}$.

Grade 1: 9.5 - $10.9 \mathrm{~g} / \mathrm{dl}$.

Grade 2: 8 - $9.4 \mathrm{~g} / \mathrm{dl}$.

Grade 3: $<8 \mathrm{~g} / \mathrm{dl}$.

2) Tinel and Phalen test technique

Tinel's test consists of applying a blow to the wrist where the median nerve passes through; a small sensation of electrical discharge is felt in one or more fingers in the sensory territory of the median nerve. In the Phalen's test, the patient's wrist is flexed, puts his hands back to back and pushes for one minute, so the presence of Carpal Tunnel Syndrome (CTS) can be evoked if one or more symptoms such as a sensation of electrical discharge or numbness are felt in the median nerve territory.

Data entry and analysis were performed using SPSS 12.0 software. The statistical test used was Pearson Chi-square 2 with $\mathrm{p}<0.05$. In order to ensure the confidentiality of the results, the anonymity of the participants was strictly respected. Verbal informed consent was obtained from patients after explanation of the purpose of the study.

\section{Results}

Out of sixty-nine (69) dialysis patients who had been on dialysis for 3 years or more, 50 patients voluntarily agreed to participate in the study, representing a participation rate of $72.46 \%$ of cases (50/69). In our study, $52 \%$ of our patients were female with a sex ratio of 1.01 . Their mean age was 50.46 years with extremes of 30 and 82 years. Seventy-five percent of the males had a B-2-M level greater than $50 \mathrm{ng} / \mathrm{l}$ (see Table 1).

Beta-2-microglobulin levels were greater than $50 \mathrm{ng} / \mathrm{l}$ in patients under 60 
Table 1. Distribution of patients by plasma beta-2-microglobulin levels and sex.

\begin{tabular}{ccc}
\hline Beta-2-microglobulin level & Male & Female \\
\hline B2M $<50 \mathrm{ng} / \mathrm{l}$ & $25 \%$ & $38.5 \%$ \\
$\mathrm{~B} 2 \mathrm{M}>50 \mathrm{ng} / \mathrm{l}$ & $75 \%$ & $61.5 \%$ \\
\hline
\end{tabular}

Chi-square $=1.039, \mathrm{ddl}=1, \mathrm{P}=0.309$.

years of age and 60 years of age or older in $63.2 \%$ and $83.3 \%$ respectively. Hypertensive nephropathy was the most common cause with $86 \%$ of cases followed by diabetic glomerulonephritis (4\%), chronic glomerulonephritis (4\%) and sickle cell disease (4\%). Hypertensive nephropathy was associated with B-2-M levels greater than $50 \mathrm{ng} / \mathrm{l}$ (see Table 2).

For hemodialysis (HD) data, the mean age of dialysis initiation was $68 \pm 64$ months with extremes of 36 and 204. Seventy-one point forty percent had B-2-M levels greater than $50 \mathrm{ng} / \mathrm{L}$ after 5 years of dialysis (see Table 3 ).

All patients were hemodialysed by a low permeability membrane (cuprophan-type membrane). The vascular approach was mainly arteriovenous fistula.

Clinically, underweight patients represented $38 \%$ of cases (19/50). Twenty percent $(20 \%)$ and four percent (4\%) of chronic dialysis patients had joint pain and sensory deficit. The pain was mainly localized in the spine, but also in the wrists, shoulder and lower limbs. In $10 \%$ of the patients, the pain radiated to the shoulder. This pain was only correlated with the level of B-2-M (see Table 4).

Clinical examination found the Phalen sign was positive in $2 \%$ ( 1 case), Tinel sign in $2 \%$ ( 1 case), while carpal tunnel syndrome was present in $2 \%$ ( 1 case). None of the patients in our series benefited from an electromyogram due to the lack of technical facilities.

Biologically, the average Beta-2-microglobulin level was $58.34 \mathrm{ng} / \mathrm{l}$ with extremes of 16.99 and $112.24 \mathrm{ng} / \mathrm{l}$ ( 8 to 51 times the upper norm). The CRP was positive in $26 \%$ of cases with a mean value of $31.99 \mathrm{mg} / \mathrm{l}$ (extremes: 0.01 and $309.78 \mathrm{mg} / \mathrm{l})$. The mean serum calcium level was $2.18 \mathrm{mmol} / \mathrm{l}$ with extremes of 1.30 and 2.64. Calcemia was within the KDIGO norm in $54 \%$ of cases. The mean phosphatemia was $1.53 \mathrm{mmol} / \mathrm{l}$ with extremes of 0.73 and $3.19 \mathrm{mmol} / \mathrm{l}$. It was within the KDIGO norm in $56.3 \%$ of cases. The PTH level was within the KDIGO norm in $36 \%$ of cases, increased in $50 \%$ of cases and decreased in $14 \%$ of cases. The number of patients with B-2-M greater than 50ng/l was greater for PTH values $>585 \mathrm{pg} / \mathrm{ml}$ (see Table 5 ).

Vitamin D deficiency was absolute and relative in $10 \%$ and $50 \%$ of cases respectively. According to KDIGO, the anemia was Grade I (32\%), Grade II (40\%), Grade III (10\%) and Grade 0 (10\%).

The mortality rate was $6 \%$ of cases. All of the deceased patients had plasma beta-2-microglobulin levels greater than $50 \mathrm{ng} / \mathrm{L}$.

Symptomatic management of pain consisted of the prescription of palliative analgesics II in $20 \%$ of cases. No median nerve-releasing surgery was performed. 
Table 2. Distribution of patients by plasma beta-2-microglobulin levels and hypertensive nephropathy.

\begin{tabular}{cccc}
\hline \multirow{2}{*}{$\begin{array}{c}\text { Hypertensive } \\
\text { Nephropathy (HTA) }\end{array}$} & \multicolumn{2}{c}{ Beta-2-microglobulin } & Total \\
\cline { 2 - 3 } & $<50$ & $33(76.7 \%)$ & $43(100 \%)$ \\
Yes & $10(23.3 \%)$ & $1(14.3 \%)$ & $7(100 \%)$ \\
To & $6(85.7 \%)$ & $34(68 \%)$ & $50(100 \%)$ \\
\hline
\end{tabular}

Chi2 = 10.792; ddl = 1; P $<0.001$.

Table 3. Distribution of patients by plasma beta-2-microglobulin level and duration on dialysis.

\begin{tabular}{ccc}
\hline \multirow{2}{*}{ Beta-2-microglobulin } & \multicolumn{2}{c}{ Duration in dialysis } \\
\cline { 2 - 3 } & $<5$ years old & $>5$ years old \\
\hline$<50 \mathrm{ng} / 1$ & $35.5 \%$ & $28.6 \%$ \\
$>50 \mathrm{ng} / 1$ & $65.50 \%$ & $71.40 \%$ \\
\hline
\end{tabular}

Chi2 = 1.96; $\mathrm{ddl}=1 ; \mathrm{P}=0.66$.

Table 4. Distribution of patients by plasma beta-2-microglobulin level and presence of pain.

\begin{tabular}{cccc}
\hline \multirow{2}{*}{ Pain } & \multicolumn{2}{c}{ Beta-2-microglobulin } & Total \\
\cline { 2 - 3 } & $<50 \mathrm{ng} / \mathrm{l}$ & $7(63.6 \%)$ & $11(100 \%)$ \\
Yes & $4(36.4 \%)$ & $27(69.2 \%)$ & $39(100 \%)$ \\
No & $12(30.8 \%)$ & $34(68 \%)$ & $50(100 \%)$ \\
Total & $16(32 \%)$ & \\
\hline
\end{tabular}

Table 5. Distribution of patients by plasma beta-2-microglobulin and intact PTH levels.

\begin{tabular}{cccc}
\hline \multirow{2}{*}{ PTH } & \multicolumn{2}{c}{ Beta-2-microglobulin } & Total \\
\cline { 2 - 3 } & $<50 \mathrm{ng} / \mathrm{l}$ & $>50 \mathrm{ng} / \mathrm{l}$ & $7(100 \%)$ \\
\hline$<130 \mathrm{pg} / \mathrm{ml}$ & $4(57.1 \%)$ & $3(42.9 \%)$ & $18(100 \%)$ \\
$130-585 \mathrm{pg} / \mathrm{ml}$ & $4(22.2 \%)$ & $14(77.8 \%)$ & $25(100 \%)$ \\
$>585 \mathrm{pg} / \mathrm{ml}$ & $8(32 \%)$ & $17(68 \%)$ & $50(100 \%)$ \\
Total & $16(32 \%)$ & $34(68 \%)$ & \\
\hline
\end{tabular}

\section{Discussion}

Accumulation of beta-2-microglobulin in the extracellular space a necessary, but probably not sufficient, condition for the occurrence of amyloidosis in dialysis patients [4]. The characteristics of the dialysis membrane, i.e. its structure, surface area, permeability and degree of biocompatibility, play an important role in variations in the serum concentration of beta-2-microglobulin in hemodialysis [4]. Most studies have compared the exclusive or near-exclusive use of cellulosic, low permeability and low biocompatibility members such as cuprophane to semi-synthetic non-cellulosic, high permeability members. The majority have 
demonstrated the superiority of synthetic membranes. For the same results, we cite Kuche's prospective study which compared 24 hemodialysis patients matched in terms of age and duration of dialysis according to the type of membrane used (cuprophane versus high-permeability synthetic polysulfone membranes) [5]. AK Cheung has shown similar results [6]. In our study, patients were dialysed exclusively with a cuprophane membrane (low permeability membrane), which explains why all patients had increased beta-2-microglobulin levels. The duration of hemodialysis plays an important role in the increase of beta-2-microglobulin [7] as well as in the development of these clinical manifestations. A beta-2-microglobulin level greater than $50 \mathrm{ng} / \mathrm{l}$ was observed in $71.4 \%$ of patients with a dialysis duration of five $(5)$ years or more $(\mathrm{P}=0.658)$ [8] [9]. One case of carpal tunnel syndrome (CCS) was clinically diagnosed in our study compared to $32 \%$ in Morocco [10]. This difference can be explained, on the one hand, by the method of detection of the carpal tunnel syndrome and, on the other hand, by the duration of haemodialysis, the average of which was higher than ours (76 \pm 12 months compared to $68 \pm 6.4$ months). The beta-2-microglobulin level was higher than $50 \mathrm{ng} / \mathrm{l}$ in $76.7 \%$ of patients with hypertensive nephropathy (0.001). B-2-M may also serve as a marker for idiopathic dilated cardiomyopathy, reflecting the different multifactorial aspects of the pathogenesis of this disease [11]. Fifty percent (50\%) of chronic hemodialysis patients with a parathyroid hormone level greater than nine times the upper norm ( $>585 \mathrm{pg} / \mathrm{l})$ had a beta-2-microglobulin level $>50 \mathrm{ng} / \mathrm{l}$. Research on the relationship of this protein with factors of bone metabolism concluded that B-2-M can be proposed as a biomarker of bone remodeling; serum values were negatively correlated with 25 hydroxy vitamin D3 and ionized calcium, and positively correlated with parathyroid hormone [12]. B-2-M is strongly implicated in the pathogenesis of dialysis amyloidosis, which is responsible for long-term osteoarticular complications [12]. Osteoarticular pain was found in $20 \%$ of patients. It was localized in the spine, wrists, shoulder and lower limbs. One study showed that beta-2-microglobulin decreased after six weeks of dialysis when a high-permeability membrane was used, but remained unchanged six years later. The use of a membrane of the same performance is therefore not sufficient to prevent amyloidosis from dialysis. Since monocytes act on the production of beta-2-microglobulin, it is justified to avoid their stimulation, therefore to use an ultra-pure dialysate (sterile and apyrogenic), with bicarbonate and not acetate. Per dialytic monitoring of beta-2-microglobulin is currently considered a quality criterion for extrarenal lavage [4]. Elevated serum concentrations of beta-2-microglobulin are found in cases of increased synthesis [4]. This is seen in lymphoid proliferation disorders: multiple myeloma (MM), lymphomas, chronic lymphoid leukaemia (CLL) and myelodysplastic syndromes (MDS). This increased synthesis is also found in inflammatory and autoimmune diseases (rheumatoid arthritis, systemic lupus erythematosus) and in CMV or HIV (AIDS) viral diseases [13] [14] [15]. 


\section{Conclusion}

In our case, the weekly rhythm of dialysis was $8 \mathrm{~h}$ per week instead of the recommended $12 \mathrm{~h}$ per week, the use of a low permeability membrane, absence of residual diuresis as well as the absence of control of the quality of dialysis water, the advanced age of some patients seem to be the major parameters of the increase of beta-2-microglobulin in hemodialysis patients. Per dialytic monitoring of beta-2-microglobulin is currently considered as a quality criterion for extrarenal purification. The important purification of beta-2-microglobulin is mainly ensured by convective phenomena and by adsorption phenomena for certain membranes.

\section{Acknowledgements}

We would like to thank all the nephrology and haemodialysis staff of the CHU du Point-G, the hospital of Kayes, Ségou, Sikasso, Mopti and Mali Gavardo hospital of Sébénicoro.

\section{Conflicts of Interest}

The authors declare no conflicts of interest regarding the publication of this paper.

\section{References}

[1] Berggard, I. and Beearn, A.G. (1968) Isolation and Properties of a Low Molecular Weight Beta-2-Globulin Occurring in Human Biological Fluids. Journal of Biological Chemistry, 243, 4095-4103.

[2] Duprat, E. (2004) MHC-Like Proteins: Phytogenesis, Structure, IGH Functions (IMGT)-LIRMM 2004. PhylogenyWorking Group Seminarsorganized by the MAB Team.

[3] Chary-Valckenaere, I. (2001) Contribution to the Pathophysiology of Dialysis Arthropathy-Aluminium and Beta-2-Microglobulin Amyloidosis. Thesis Med Nancy.

[4] Anociar, M.R., Idmoursa, A., El Jahiri, Y., Boukhira, A., Beraou, A. and Chella, S. (2011) Interest in Determination of Beta-2-Microglobulin in Biological Samples. Revue Francophone des Laboratoires, 436, 77-82. https://doi.org/10.1016/S1773-035X(11)71160-1

[5] Kuchle, C., Fricke, H., Held, E. and Schiff, H. (1996) High-Flux Hémodialysis Postpones Clinical Manifestation of Dialysis-Related Amyloidosis. American Journal of Nephrology, 16, 484-488. https://doi.org/10.1159/000169048

[6] Cheung, A.K., Greene, T., Leypoldt, J.K., et al. (2008) Association between Serum $\beta_{2}$-Microglobulinlevel and Infectorious Mortality in Hémodialysis Patients. Clinical Journal of the American Society of Nephrology, 3, 69-77. https://doi.org/10.2215/CJN.02340607

[7] Al-Taee, I.K., Al-Safar, J.J., Al-Falahi, Y.S. and Al-Shanima, I.A. (2003) The Clinical Significance of Béta2-Microglobulineinend Stage Renal Disease. Saudi Journal of Kidney Disease and Transplantation,14, 492-496.

[8] Alhomrany, M.A., Khan, M.R., Adzakut, F. and Hardnig, M.G. (2001) Carpel Tunnel Syndrome in Hemodialysis Patients: Early Detection by electro Neurophysiological 
Studies. Nephrology, 6, 259-262. https://doi.org/10.1046/j.1440-1797.2001.00061.x

[9] Okuno, S., Ishimura, E. and Kohno, K. (2009) Serum $\beta_{2}$-Microglobuline Level Is a Significant Predictor of Mortality in Maintenance Hémodialysis Patients. Nephrology Dialysis Transplantation, 24, 577-577. https://doi.org/10.1093/ndt/gfn521

[10] M'Barki, H. (2011) Carpal Tunnel Syndromes in Chronic Hemodialysis Patients. Thesis Med, Fes, No. 119/11.

[11] Klappacher,G., Mundigler, G., Papousek, A., et al. (1993) Elevated Circulating Levels of Beta 2-Microglobuline in Patients with Idiopathie Dilated Cardiomyopathy. American Journal of Cardiology, 71, 119-121. https://doi.org/10.1016/0002-9149(93)90723-P

[12] Ouesada, J., Alouso, J., Gonzalez, J., Muñoz, R., Jans, I., Martiu, A. and Bouillon, R. (1998) Serum $\beta$-2-Microglobulin Is a Marker of High Bone Remodelling in Elderly Women. Mechanisms of Ageing and Development, 102, 293-298. https://doi.org/10.1016/S0047-6374(98)00019-0

[13] Floege, J. and Ketteler, M. (2001) $\beta$-2-Microglobulin-Derived Amyloidosis an Update. Kidney International, 59, 164-171. https://doi.org/10.1046/j.1523-1755.2001.59780164.x

[14] Hamel, B., Brandissou, S., Granolleras, C., et al. (1997) Charactéristics of Membranes Used in Hemodialysis. The Journal of Clinical Pharmacology, 16, 7-12.

[15] Vandenbroucke, J.M., Huaux, J.P., Noel, H., et al. (1998) Synovial and Bone Amyloidosis: Biocompatibility Phenomenon of Hémodialysis. Kidney International, 33, 35-36. 